\title{
Smart Online Grocery Shopping App Development
}

\author{
Abdulhaseeb H. abdulmalik ${ }^{* 1}$, Faisal Sulaiman A. Alghafri ${ }^{2}$ and Mohammed J. Yousif ${ }^{* 3}$ \\ ${ }^{1,2}$ Faculty of Computing \& Information Technology, Sohar University, Oman. \\ * Corresponding author: Abdulhaseeb H. abdulmalik, hhaseeb908@gmail.com \\ * Corresponding author: Mohammed J. Yousif, mohyou200210@gmail.com
}

\begin{abstract}
Shopping is one of the activities that some people consider part of their life, while others do not even think of it. This comparison makes us discover people's problems with shopping. People have shopping problems such as limited time, expats in foreign countries without cars, a transportation issue, people consider physical shopping as a waste of time, health issues, long-distance to market. And the difficulty in obtaining some items. As the problems mentioned above, we have explored our idea, which is related to personal shopping. Therefore, we have built an application that combines different market shops, i.e. (Malls, supermarkets, and pharmacies). This personal grocery shopping is an innovative app that allows the customers to get all their needs and suggest items based on previous history. Then deliver items to their doorstep and can facilitate online shopping procedure where customers can browse unlimited products all at one time. This work supports people in exploiting their time to be safer and more accessible than wasting it physically. Moreover, people can order the product from home instead of going around for long distances for shopping. In addition, this app could help people who are facing health problems and unable to buy something physically to avoid future problems. Finally, some people do not have transportation methods for shopping, and they should keep pace with the evolution.
\end{abstract}

Keywords: Online Grocery; Mobile app; Smart association; Data mining; Data extraction medium, provided the original work with proper citation. This work is licensed under Creative Commons Attribution International License (CC BY 4.0). 


\section{Introduction}

Economic growth helps to the global expansion of e-commerce, as increased income and confidence increase the demand for online services, which expands the number of suppliers and the size of their delivery networks ( $\mathrm{Li}, \mathrm{C}$ et al. 2020). However. The Global retail e-commerce sales were decelerating to $16.5 \%$ in 2020 compared to 2019, with 20.2\% last year, as shown in Figure 1. Secure Mobile applications are one of the technologies that are spread rapidly and increasingly worldwide over the past decade. It makes the user trust online shopping, which increases the number of customers and trade. During the COVID-19 pandemic, people have shifted their perspectives from marketplaces to apps to limit the spread of the virus. Most shops, malls, and markets are using their applications, while delivery applications are, on the other hand, Talabat.com.

\begin{tabular}{l}
\hline $\begin{array}{l}\text { Retail Ecommerce Sales Worldwide, by Region, } 2020 \\
\text { billions }\end{array}$ \\
\hline \begin{tabular}{l} 
Asia-Pacific \\
North America $\$ 2,448.33$ \\
\hline
\end{tabular}$\$ 449.00 \quad$ Western Europe \\
$\$ \$ 92.91 \quad$ Central \& Eastern Europe \\
$\$ 83.63$ Latin America \\
$\$ 41.56$ Middle East \& Africa \\
\hline
\end{tabular}

Figure 1. the global-ecommerce sale (Emarketer, 2020)

Grocery shopping is an experience during the pandemic, which helps us buy the products and items online easily and smoothly. The Grocery shopping application simplifies all shopping procedures, facilitates payment methods, and enhances UI interaction so that the user's first-time experience could be the best practice. Users can use this grocery app, it includes smooth use, comfortable interaction, and elastic enhancements better than other grocery applications. The reports recorded that U.S. online grocery sales grew 22\% in 2019 because of the high demand from general COVID-19. However, it is increased by about 40\% i 2020 (Supermarketnews, 2020), as shown in Figure 2.

Several studies explored the implementation of online grocery shopping systems. The past decade has Proposed significant developments in mobile commerce (mobile commerce), which opens up severe prospects in the future to increase the size and transmission of trade (Wong et al., 2012; Yang and Kim, 2012). The new development in the mobile phone leads to almost every home through the services and advantages. This led companies to create services 
called m-services that help customers browse or buy products and services from merchants via mobile devices anywhere and anytime (Hung et al., 2012; Yang \& Kim, 2012).

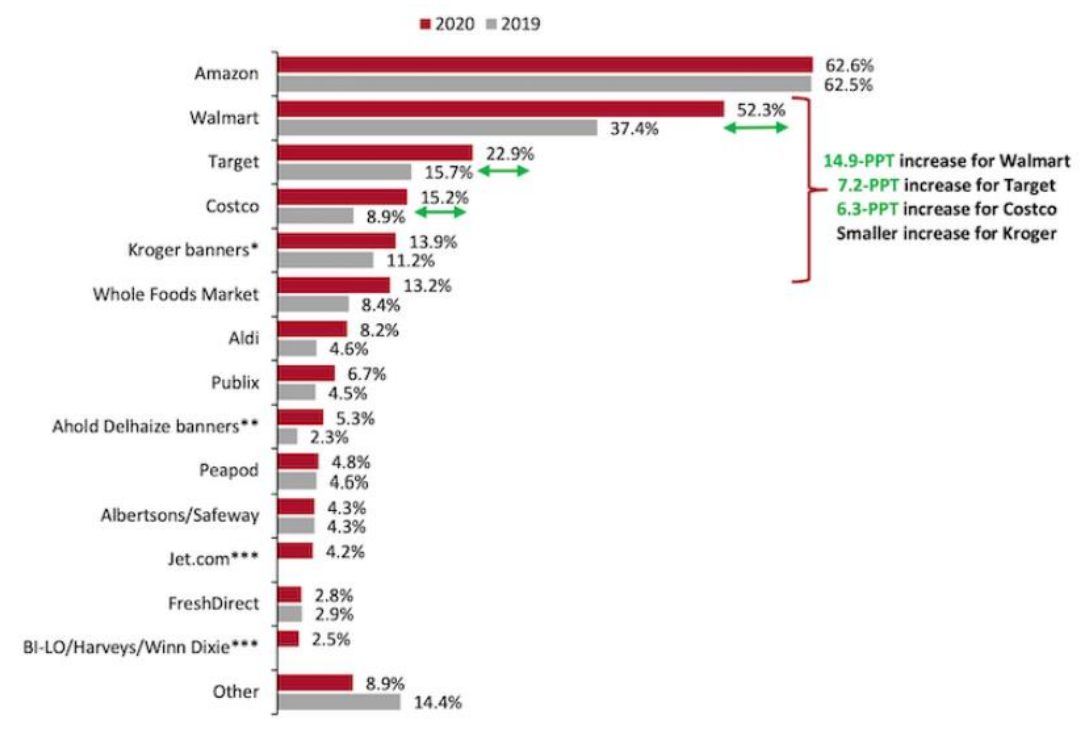

Figure 2: Online Grocery Shoppers (Supermarketnews, 2020)

Besides, many recent researchers have investigated the factors that impact the customer purchasing behavior in online grocery shopping systems, which include the delivery costs (Goethals et al., 2012; Pozzi, 2012; Schmid \& Axhausen, 2019) and delivery times (Agatz et al., 2011; Köhler et al., 2020; Strauss et al., 2020). The proposed grocery is an intelligent app that provides many features such as offers and the latest products with the highest quality, which people and families can use. It contains different categories targeting all levels of users, including electronics, sports, and households. Those features are all to attract customers with their various preferences. We aim to be a point of confidence among the Omani community with high products, service quality, and communication with users in general. Furthermore, it is more flexible and elastic in communication queries and security systems to feel more confident to share their information. Applications, in general, can facilitate people's lives faster; we worked with everything we could to simplify our application in the form of grocery so that people in our dear country can keep pace with development.

The extensive literature review is helped to identify the research gaps in the area of online shopping. The summary of critical research gaps includes the following:

1. Online shopping grocery has exponential growth, become a fascinating area for research because of the new requirements of new life and the COVID-19 situation. Therefore, it is interesting to study the factors that affect consumers' behavior towards online shopping groceries. 
2. Limited experimental research has been carried into measuring the attributes of online shopping grocery buying/selling behavior in a rapidly changing e-commerce market and rapidly increasing smartphone usage.

3. There is no complete examination of the wide range of factors, including (security, trust, service support, flexible transactions, and price promotions) and their impact on buying behavior towards online shopping groceries.

4. Typical applications for shopping groceries attract many clients because of the several facilities and the variety of services, which include (delivery services, price comparison, grocery discount).

In this work, we will fill the research gaps by developing and examining a conceptual model for online grocery shopping and the factors that impact the customer's attitude. And then develop intelligent mobile apps that can respond to all customer needs and e-commerce characteristics like an expert system (AlKishri \& Al-Bahri, 2021).

\section{Proposed system and Objectives}

The proposed Online Grocery shopping is an intelligent multistage mobile application that helps customers shop and delivers the needed items quickly and safely. It is implemented smart data mining that records the customer history and aggregates the things based on the customer needs. It sends notifications related to new items and offers, as shown in Figure 3. The Flutter programming language and android studio software are used to implement the proposed mobile application for online grocery shopping that works with different operating systems (Android and IOS).

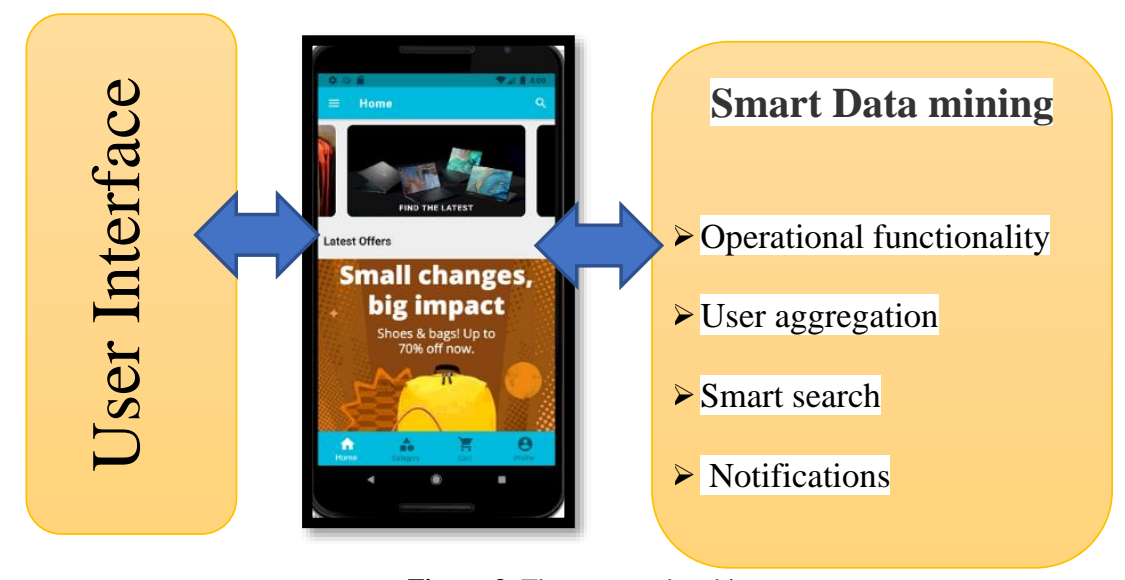

Figure 3. The proposed architecture

This work aims to achieve the following goals:

1. Conduct a critical literature survey of previous studies to identify the critical features affecting consumers behavior.

2. Develop the conceptual model for the online grocery shopping app that offer different facilities such as secure, fast, low prices.

3. Develop a smart module that aggregates the customer needs based on demographics attributes. 
4. Develop and implement the online grocery shopping app that works with different operating systems (Android and IOS).

\section{Competitive Profile Matrix}

A competitive profile matrix is a method that measures and compares between companies or an application, through the points of weaknesses and strengths. CPM matrix helps us to compare between those related works we have discussed that are like Grocery Personal Shopping such as "Talabat", "OpenSouq", and "AliExpress" in order to understand our external environment where it shows that "OpenSouq" and "Talabat" got 2.85 scores as the strongest competitor to our Grocery Personal Shopping in Table 1.

Table 1. Competitive Profile Matrix

\begin{tabular}{|c|c|c|c|c|c|c|c|}
\hline \multicolumn{8}{|c|}{ Competitive Profile Matrix } \\
\hline & & \multicolumn{2}{|c|}{ AliExpress $\rightleftharpoons$} & \multicolumn{2}{|c|}{ Talabat $\square$} & \multicolumn{2}{|c|}{ OpenSouq $=$} \\
\hline $\begin{array}{l}\text { Critical success } \\
\text { factors }\end{array}$ & Weight & Rating & Score & Rating & Score & Rating & Score \\
\hline $\begin{array}{l}\text { Build Reputation } \\
\text { and Establish } \\
\text { Credibility }\end{array}$ & 0.1 & 3 & 0.3 & 3 & 0.3 & 2 & 0.2 \\
\hline Advertising & 0.1 & 3 & 0.3 & 4 & 0.4 & 2 & 0.2 \\
\hline $\begin{array}{c}\text { Loyal Customer } \\
\text { Base }\end{array}$ & 0.05 & 2 & 0.1 & 3 & 0.15 & 3 & 0.15 \\
\hline $\begin{array}{l}\text { domestic market } \\
\text { penetration }\end{array}$ & 0.2 & 2 & 0.4 & 2 & 0.4 & 3 & 0.6 \\
\hline $\begin{array}{l}\text { Clear Market } \\
\text { Position }\end{array}$ & 0.08 & 2 & 0.16 & 3 & 0.24 & 3 & 0.24 \\
\hline $\begin{array}{l}\text { Multiple payment } \\
\text { methods }\end{array}$ & 0.1 & 4 & 0.4 & 3 & 0.3 & 1 & 0.1 \\
\hline $\begin{array}{l}\text { Design of the } \\
\text { store }\end{array}$ & 0.1 & 2 & 0.2 & 4 & 0.4 & 3 & 0.3 \\
\hline Customer service & 0.1 & 2 & 0.2 & 3 & 0.3 & 4 & 0.4 \\
\hline $\begin{array}{c}\text { Ability To } \\
\text { Quickly Adopt } \\
\text { New Technology }\end{array}$ & 0.02 & 2 & 0.04 & 3 & 0.06 & 3 & 0.06 \\
\hline Products range & 0.15 & 3 & 0.45 & 2 & 0.3 & 4 & 0.6 \\
\hline TOTAL & 1 & & 2.55 & & 2.85 & & 2.85 \\
\hline
\end{tabular}

\section{Proposed App Implementation and Setup}

This section will present the implementation of the mobile shopping grocery and new development in information technology and image processing (Al-Hatmi \& Yousif, 2017; Yousif, 2011). This application is an online mobile app that works with different platforms, such as android and IOS. Also, it offers various functions that facilitate the customer needs and introduce multi-functions, such as push notifications and intelligent data aggregation (Abusham \& Al.Zaabi, 2021). A secure database that saves user information privately and does not 
share this information with anyone other. In addition, a secure payment method using PayPal and other trust methods. Figure 4 presents the USE-Case diagram that shows the actors and the main function in the proposed system, which has two main actors (admin and user). The guest can see only the first screen of the application. A pop-up message will appear after a certain period asks the quest to complete the registration process. The user with an account can uses logins to the system, orders the product and pay its price in the system (app). The administrator (admin actor) has the authorization and permission to manage the system activities, as shown in Figure 4.

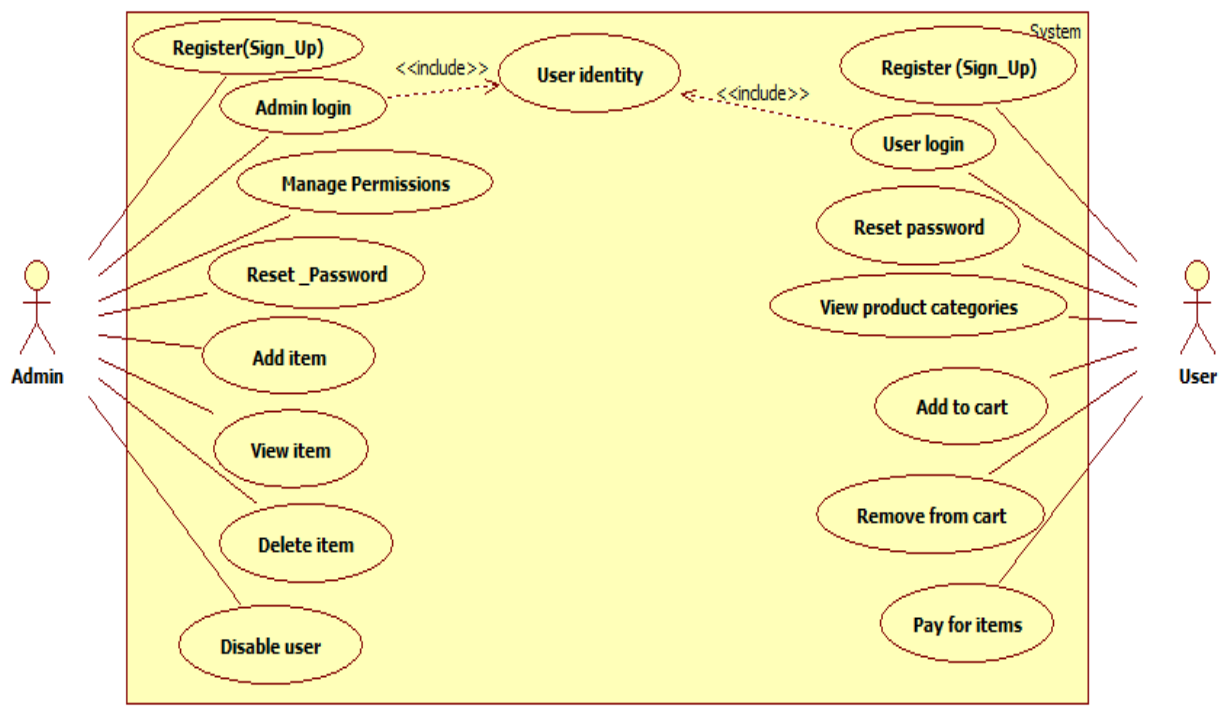

Figure 4. the USE-Case diagram of the proposed app

Figure 5 shows the app home screen that shows the new offers and the user functions, such as add to cart, view items, payment for the cart, rest password, edit user information, etc. The home screen includes the navigation bar, carousel, and side menu bar. The navigation bar consists of functions, such as Home, Category, Cart and profile. Each of those categories has its own screen in android studio for better use, and for continuous updating of data. Because it is a dynamic application that has fast changing data and changing prices; therefore, several screens are distributed to enables the admin to update the list of items, prices, and sale offers quickly and accurately. Figures 6 and 7 present the sign-up and login screen, which enables the user to login into the system or the guest to register an account. If the user forgets password, then the user can press forget the password and enter the registered email, so the recovery process is running. Figure 8 shows the side menu screen that includes about us, settings, privacy policy, terms and conditions, and logout. Figures 9 and 10 show the items categories and subcategories that include item specifications, such as name, description, rate (\#Stars \& \#like), price, and add to cart. 


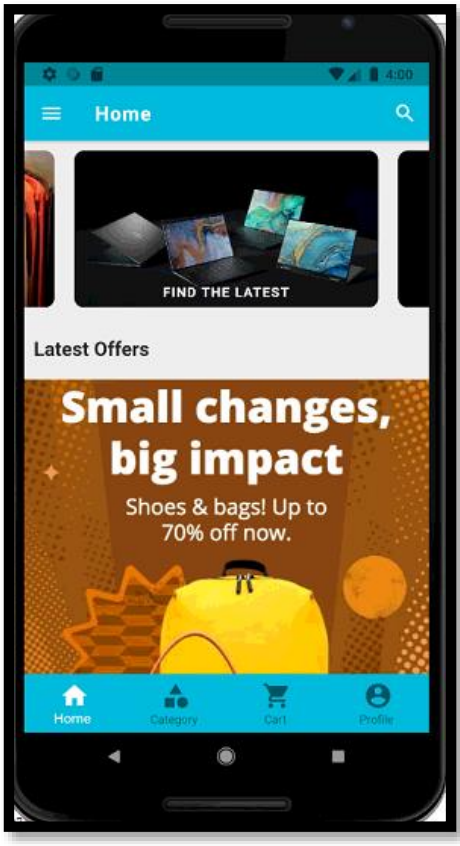

Figure 5. app home screen

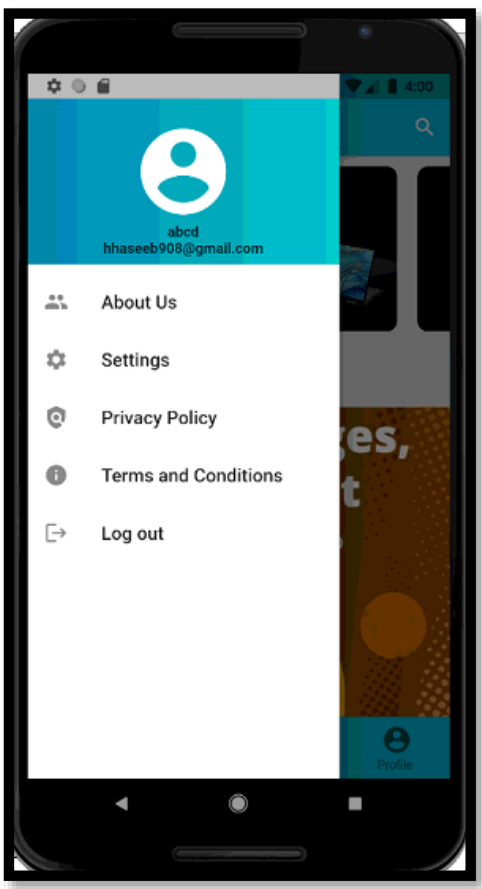

Figure 8. app side menu

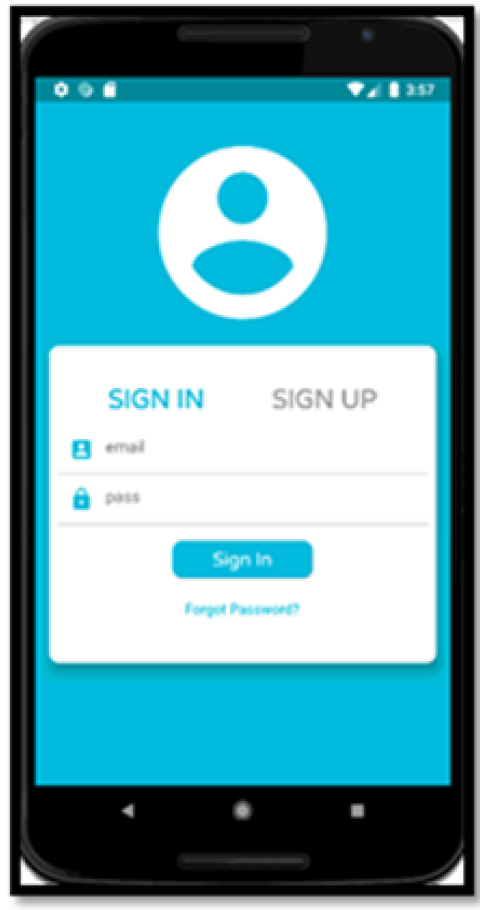

Figure 6. app sing up screen

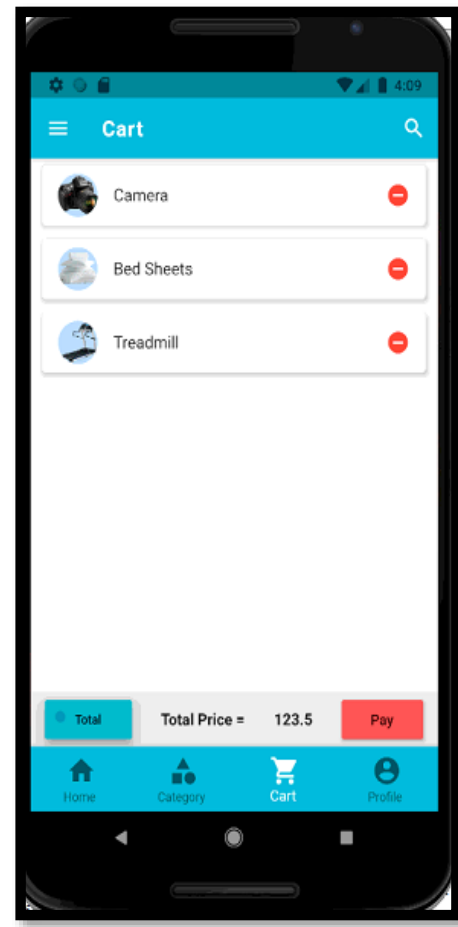

Figure 9. app Category screen

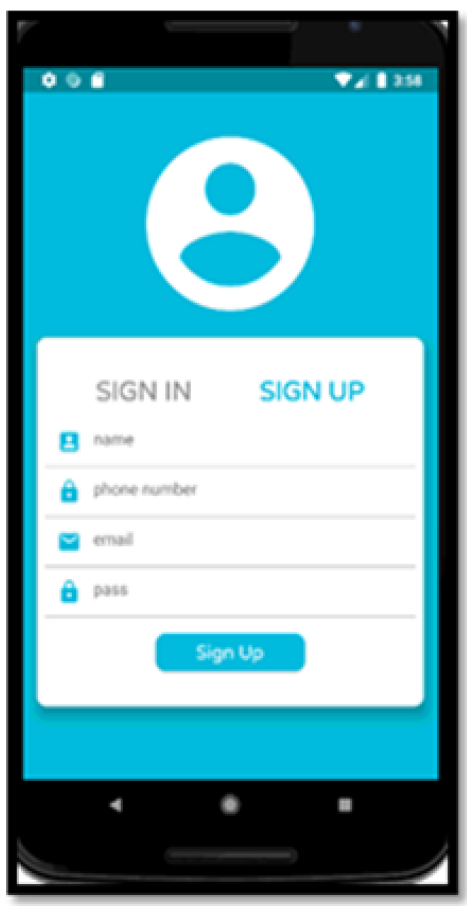

Figure 7. app log in screen

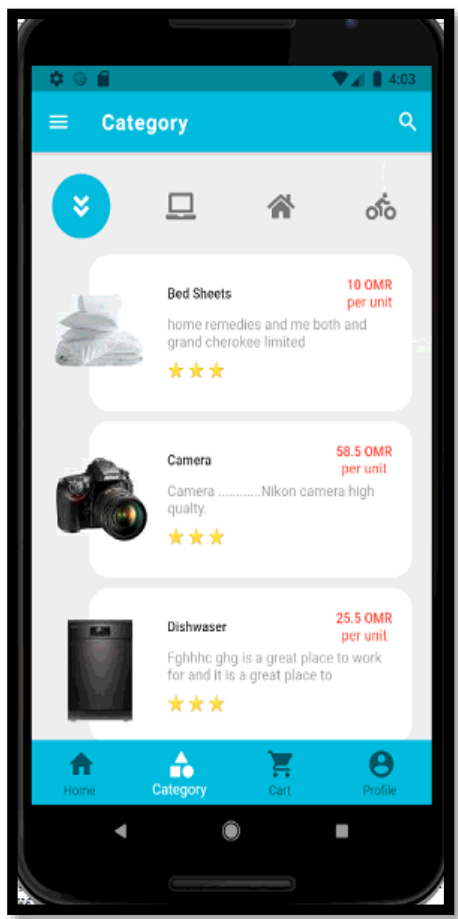

Figure 10. app Sub-category screen

Once the user adds the items in cart as shown above, there will be two functions for completing shopping process. 
- Total functions: collects the total value if the products and purify the result for the user.

- Pay function: once the total price of the products is appeared, then the user can pay the amount to complete purchasing process.

Figure 11 shows an example of item description and add to cart function. After the user adds the item into the cart, a message shows as "your item add to the cart" as shown in Figure 12. Then, the user will receive conformation email to pay by either PayPal or cash.

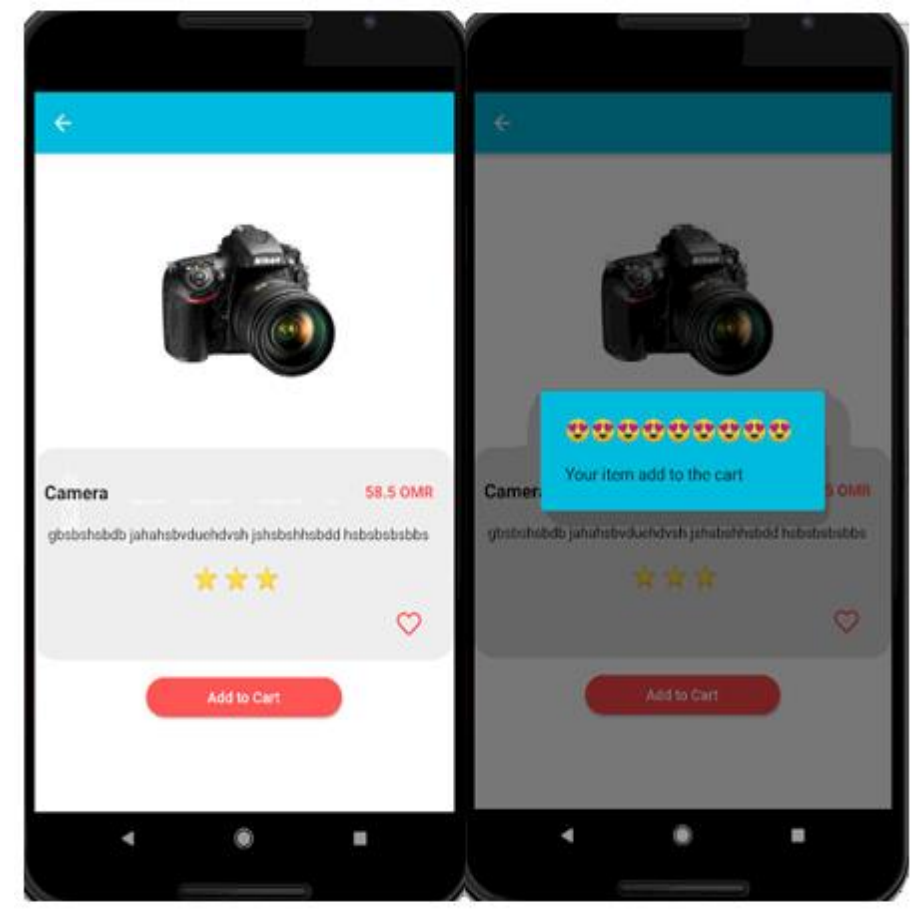

Figure 11 app item description screen

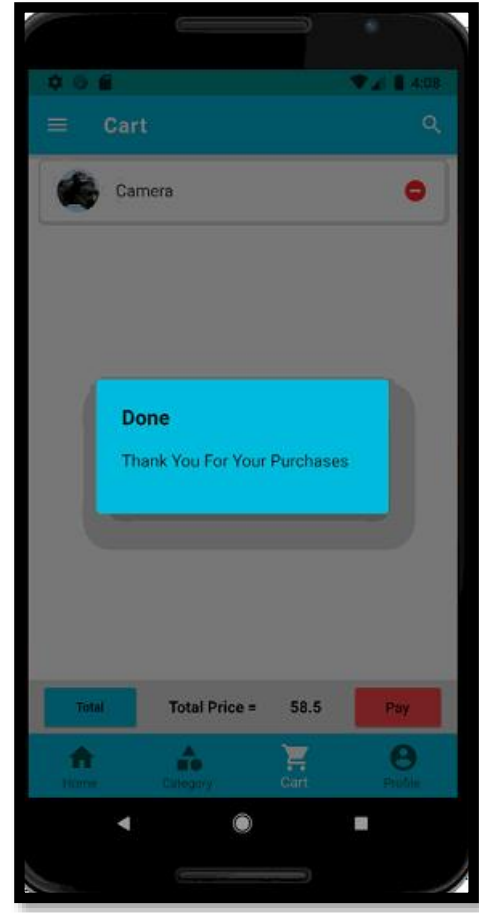

Figure 12. app Sub-category screen

The scope of this work serves principles of E-commerce, which includes user Friendliness, ease in navigating, unique Design, emphasis on Security, target customers, quick Search menu, informative product descriptions, and truest app. Besides, serving the ethical codes in keeping users' information away from any alteration or share in the public domain.

\section{Conclusion \& Future Work}

The preventive situation due to Covid-19 imposed a ban on movement and the need to distance. Here appears the importance of having a mobile app for sale via the Internet that provides an easy and safe way to shop and reduce the trouble of moving between markets. You can have different brands' products in various components of a country, 
country, or possibly globally instead of being restricted by geography. The current application lets you shopping while you are at your home and a convenient way to shop at any time in the morning or evening and from anywhere, quickly and safely. It also saves the hassle of moving between stores and browsing various goods in one place and at competitive prices lower than the price in the supermarket with the constant offers of cheap deals.

It offers weekly and monthly sales and discounts for membership holders, saving money compared to purchasing from multiple locations and retail. The easy search feature is also provided by the name of the material or its classification by quickly and conveniently access the required materials. The comparison feature also provides a way to get the desired product at the lowest price by comparing all prices and finding the best deal that fits your budget the most. The application also provides multiple means of online payment, which saves the customer from exchanging currency or finding the necessary amount of currency. The innovative aggregation feature also saves time in viewing previous or always-purchased items with every new shopping. This application provides privacy for buying and selling without embarrassment. Online stores are good for discreet purchases of things like embarrassing things, underwear, etc. This allows you to buy lingerie without the shame or paranoia that humans are looking at me.

Future directions for the development of the application are to link the tab with the most significant number of international stores to provide various goods of number, type, and classification. The application also connects with delivery companies globally and locally for faster delivery. Marketing the application locally and globally will increase the number of users, leading to an increase in demand, supply, and exchange of ideas to improve services.

\section{Acknowledgment}

The research leading to these results has no Funding.

\section{References}

[1]. Abusham, E. A., \& Al. Zaabi, A. M. (2021). Smartphone application for Self - Management Diabetes: A review. Applied Computing Journal, 1(Issue 1), 25-37. https://doi.org/10.52098/acj.202116

[2]. Al-Hatmi, M. O., \& Yousif, J. H. (2017). A review of Image Enhancement Systems and a case study of Salt \&pepper noise removing. International Journal of Computation and Applied Sciences (IJOCAAS), 2(3).

[3]. AlKishri, W., \& Al-Bahri, M. (2021). Expert system for identifying and analyzing the IoT devices using Augmented Reality Approach. Artificial Intelligence \& Robotics Development Journal, 43-57.

[4]. Agatz, N.; Campbell, A. (2011), Fleischmann, M.; Savelsbergh, M. Time slot management in attended home delivery. Transp. Sci., 45, 435-449.

[5]. Emarket, (2020). Accessed 20/4/2021, https://www.emarketer.com/content/global-ecommerce-2020.

[6]. Goethals, F.; Leclercq-Vandelannoitte, A.; Tütüncü, Y. (2012). French consumers' perceptions of the unattended delivery model for e-grocery retailing. J. Retail. Consum. Serv., 19, 133-139. 
[7]. Köhler, C.; Ehmke, J.F.; Campbell, A.M. (2020). Flexible time window management for attended home deliveries. Omega 2020, 91, 102023.

[8]. Li, C., Mirosa, M. and Bremer, P., (2020). Review of Online Food Delivery Platforms and their Impacts on Sustainability. Sustainability, 12(14), p.5528.

[9]. Pozzi, A. (2012). Shopping cost and brand exploration in online grocery. Am. Econ. J. Microecon , 4, 96-120.

[10]. Schmid, B.; Axhausen, K.W. (2019) In-store or online shopping of search and experience goods: A hybrid choice approach. J. Choice Model, 31, 156-180.

[11]. Strauss, A., Gülpınar, N., \& Zheng, Y. (2020). Dynamic pricing of flexible time slots for attended home delivery. European Journal of Operational Research.

[12]. Supermarketnews, (2020). Accessed 20/4/2021 https://www.supermarketnews.com/online-retail/online-grocery-salesgrow-40-2020.

[13]. Wong, C.H., Lee, H.S., Lim, Y.H., Chua, B.H., Chai, B.H. and Tan, G.W.H. (2012), Predicting the consumers' intention to adopt mobile shopping: an emerging market perspective., International Journal of Network and Mobile Technologies, Vol. 3 No. 4, pp. 24-39

[14]. Yang,K.and Kim,H.-Y.(2012). Mobile shopping motivation: an application ofmultiple discriminant analysis, International Journal of Retail \& Distribution Management, Vol. 40 No. 10, pp. 778-789

[15]. Yousif, J. H. (2011). Information Technology Development. LAP LAMBERT Academic Publishing, Germany ISBN 9783844316704.

\begin{abstract}
(c) 9 Author(s) and ACAA permit unrestricted use, distribution, and reproduction in any medium, provided the original work with proper citation. This work is licensed under Creative Commons Attribution International License (CC BY 4.0).
\end{abstract}

